\title{
Medievalista
}

Online

$22 \mid 2017$

Número 22

\section{Luz, cor e ouro: estudos sobre manuscritos iluminados. Lançamento de e-book apresentação da base de dados ManuscriPT}

Studies on illuminated manuscripts. E-book and ManuscriPT data base presentation

\section{Ana Paiva Morais}

\section{OpenEdition}

\section{Journals}

\section{Edição electrónica}

URL: http://journals.openedition.org/medievalista/1394

DOI: 10.4000/medievalista.1394

ISSN: $1646-740 X$

\section{Editora}

Instituto de Estudos Medievais - FCSH-UNL

\section{Refêrencia eletrónica}

Ana Paiva Morais, «Luz, cor e ouro: estudos sobre manuscritos iluminados. Lançamento de e-book apresentação da base de dados ManuscriPT », Medievalista [Online], 22 | 2017, posto online no dia 01 dezembro 2017, consultado o 23 setembro 2020. URL : http://journals.openedition.org/medievalista/ 1394 ; DOI : https://doi.org/10.4000/medievalista.1394

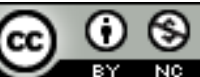

Mediavalista está licenciado com uma Licença Creative Commons - Atribuição-NãoComercial 4.0 Internacional. 
Título / Title: Luz, cor e ouro: estudos sobre manuscritos iluminados. Lançamento de e-book apresentação da base de dados ManuscriPT / Studies on illuminated manuscripts. E-book and ManuscriPT data base presentation

Autor(es) / Author(s): Ana Paiva Morais

Universidade / University: Universidade Nova de Lisboa

Faculdade e Departamento / Unidade de Investigação - Faculty and Department /

Research Center: Faculdade de Ciências Sociais e Humanas. Departamento de Línguas,

Culturas e Literaturas Modernas / Instituto de Estudos de Literatura e Tradição

Código Postal: 1269-061

Cidade / City: Lisboa

País / Country: Portugal

Email Institucional / Institutional email: anapm@fcsh.unl.pt

Fonte: Medievalista [Em linha]. Direc. Bernardo Vasconcelos e Sousa. Lisboa: IEM.

Disponível em:

http://www2.fcsh.unl.pt/iem/medievalista/MEDIEVALISTA22/morais2214.html

ISSN: 1646-740X

Data recepção do artigo / Received for publication: 12 de Maio de 2017 


\section{Luz, cor e ouro: estudos sobre manuscritos iluminados. Lançamento de e-book e apresentação da base de dados ManuscriPT / Studies on illuminated manuscripts. E-book and ManuscriPT data base presentation} Ana Paiva Morais

Teve lugar no dia 7 de Março, pelas 17h30, na Biblioteca Nacional de Portugal (BNP), o lançamento do e-book Luz, cor e ouro. Estudos sobre manuscritos iluminados, coeditado pela BNP e pelo Instituto de Estudos Medievais da Faculdade de Ciências Sociais e Humanas da Universidade Nova de Lisboa (IEM-FCSH/NOVA), e coordenado por Catarina Fernandes Barreira.

Foi igualmente feita a apresentação da Base de Dados ManuscriPT: Manuscritos iluminados em Portugal ${ }^{1}$, onde se poderá encontrar as descrições dos códices e do seu conteúdo - Fichas Científicas de Manuscritos. Este projeto está a ser desenvolvido pelo IEM, em parceria com o Departamento de Conservação e Restauro da Faculdade de Ciências e Tecnologia da Universidade Nova de Lisboa (DCR-FCT/NOVA). A coordenação do projecto está a cargo da equipa constituída por Catarina Fernandes Barreira, Conceição Casanova, Ana Lemos e Luís Campos Ribeiro.

O e-book reúne um conjunto de dezasseis textos, da autoria de mais de duas dezenas de investigadores sobre manuscritos iluminados e livros impressos, produzidos a partir do seminário mensal Um mês, um códice iluminado, uma iniciativa conjunta entre o IEM e a BNP. A apresentação desta obra que aqui publicamos esteve a cargo de Ana Paiva Morais, professora do Departamento de Línguas, Culturas e Literaturas Modernas da FCSH/NOVA e Directora do Instituto de Estudos de Literatura e Tradição (IELT-FCSH/NOVA).

\footnotetext{
${ }^{1}$ Disponível em www.fcsh.unl.pt/manuscript/pt/projecto
} 


\section{Cor, luz e ouro: estudos sobre manuscritos iluminados \\ Sessão de apresentação e lançamento do livro - Biblioteca Nacional de \\ Portugal}

O ebook Luz, cor e ouro: estudos sobre manuscritos iluminados, editado numa parceria entre a Biblioteca Nacional de Portugal e o Instituto de Estudos Medievais da Faculdade de Ciências Sociais e Humanas da Universidade Nova de Lisboa, surge em boa hora. Poderia começar a minha apresentação recorrendo a este topos inclusivo da apresentação de obras que constituem estudos científicos. Em vez desta afirmação, que é por demais óbvia, prefiro iniciar a minha exposição pela confissão de uma perplexidade: quando a coordenadora desta obra, a Doutora Catarina Barreira, me pediu que fizesse a respetiva apresentação disse-me que se esperava "uma visão diferente e exterior da que normalmente têm os investigadores que trabalham o tema", e na verdade, a minha leitura não pode deixar de ser a de uma estranha, para não dizer a de uma estrangeira, de alguém que, verdadeiramente habita paragens distantes das dos artigos que compõem esta obra, na maioria dos casos, mais habituada que estou a lidar com problemas hermenêuticos da produção poética medieval.

A minha perplexidade é, melhor dizendo, um conjunto de perplexidades: desde logo o caráter verdadeiramente excecional de multidisciplinaridade desta obra que, centrandose no estudo de um conjunto de manuscritos, abarca disciplinas tão variadas quanto a história, a história da arte, a musicologia, a história da ciência, a codicologia, estudos de iconografia (focando em particular a iluminação dos manuscritos), a "literatura", a filosofia ou a teologia, mas sempre com uma preocupação em mente, que eu resumiria do seguinte modo, parafraseando Adelaide Miranda e Maria João Melo no seu estudo de abertura do livro - focar a materialidade dos manuscritos iluminados medievais como um aspeto central na produção de arte e de cultura no período medieval, onde materialidade, texto e imagem se conjugam numa admirável dinâmica de significação².

\footnotetext{
2 MIRANDA, Adelaide; MELO, Maria João - "O manuscrito iluminado medieval. Materialidade, arte e cultura”. in BARREIRA, Catarina Fernandes (coord.) - Luz, cor e ouro estudos sobre manuscritos iluminados. [Em linha] Lisboa: Biblioteca Nacional de Portugal/Instituto de Estudos Medievais, ISBN 978-972-565-600-6. Disponível em www.myebooks.pt/book/luz-cor-e-ouro-estudos-sobre-manuscritosiluminados/H0IOY3, p. 27-28.
}

Medievalista online № 22 | Julho - Dezembro 2017 ๑ IEM - Instituto de Estudos Medievais 3 www2.fcsh.unl.pt/iem/medievalista 
Tal é admiravelmente posto em prática numa obra polifónica - porque, de resto, emergiu de um trabalho coletivo a várias vozes realizado nas sessões do ciclo de seminários mensais Um mês, um códice iluminado, um verdadeiro calendário falado colocando especial enfoque em objetos específicos tão díspares quanto as iluminuras e, de um modo mais geral, a iconografia, o manuscrito medieval enquanto códice, as iniciais ou diagramas, aspetos codicológicos diversos, a letra na sua conjugação com o canto, as encadernações e elementos musicológicos de livros de coro, reunindo este conjunto de trabalhos análises teóricas e análises laboratoriais especializadas, como se afirma no estudo inicial de Maria Adelaide Miranda e Maria João Melo, tudo isto alcançando um elevado grau de conhecimento técnico dos manuscritos muito especializados.

Os géneros percorridos nesta obra são também de grande alcance - abarcando os apocalipses, bestiários, bíblias, entre as quais as bíblias de bolso na livraria de Alcobaça e a Bíblia de Cervera - este último numa incursão interessantíssima num manuscrito sefardita -, manuais universitários, um “vocabulário”, cantigas galego-portuguesas, livros de horas, um tratado de fisionomia, tratados de medicina e de dietética, livros de coro e livros de cavalarias, mas também textos e imagens representativos das arte de falar por sinais. As obras referidas estão conservadas, muitas delas em manuscritos da Biblioteca Nacional de Portugal, mas também da Biblioteca da Ajuda e do Arquivo Nacional da Torre do Tombo, e provêm de fundos dos Mosteiros de Alcobaça, do Lorvão, de Santa Cruz de Coimbra ou, ainda, de Nossa Senhora da Anunciada em Lisboa, mas também de proveniência internacional, como é o caso do livro de horas, Il. 19, originário do noroeste da França, e do Il. 15, um livro de horas flamengo, ou o Il. 165, que contém as Horas da rainha D. Leonor que terá entrado em Portugal a partir de Castela, como demonstra Delmira Espada Custódio.

As obras que estão na base dos trabalhos que aqui se publicam cobrem um vasto leque da produção medieval, o que só por si atesta a importância da imagem no códice nos vários domínios da cultura e do conhecimento durante o período medieval, como se vê em alguns exemplos aqui estudados de impressos de obras produzidas na Idade Média, ou produzidas a partir do seu fundo cultural. Essa latitude vai desde as bíblias, representadas por uma bíblia de bolso da livraria de Alcobaça, estudada por Luís 
Correia de Sousa, e a Bíblia de Cervera, que mereceu uma estimulante análise de José A. Ramos, Luís Urbano Afonso e Tiago Moita, e os livros de devoção como o livro de Horas da rainha D. Leonor e dois outros livros de horas, os Iluminados 15 e 19 da Biblioteca Nacional de Portugal, estudados respetivamente por Delmira Espada Custódio e por Ana Lemos, Rita Araújo e Conceição Casanova e a tratados científicos como o De Physionomia de Rolando de Lisboa, examinado por Helena Avelar de Carvalho e Luís Campos Ribeiro, e o Regimento do Corpo de Aldobrandino de Siena, também assinado por Luís Campos Ribeiro, passando pelas cantigas galegoportuguesas, de que Graça Videira Lopes traça o percurso especificamente a partir do Cancioneiro da Biblioteca Nacional, e a Chronica do emperador Clarimundo, obra impressa em 1522, aqui estudada com base na edição setecentista depositada na sala dos reservados da Biblioteca Nacional de Portugal por Rosário Santana Paixão, por obras especificamente musicais como os livros de coro - o Antifonário L.C. 131, estudado por Paula Cardoso e o Iluminado 115 a que Manuel Pedro Ferreira dedica o último artigo desta coletânea. Passa-se, ainda, pelos quatro livros das Sentenças de Pedro Lombardo, proveniente do Mosteiros de Santa Maria de Alcobaça, que Catarina Barreira examina na sua função de manual universitário no contexto da abadia, o De Avibus de Alcobaça, num estudo de Rita Castro, Maria João Melo e Adelaide Miranda, o Vocabulário de Papias e o De Computo de Rábano Mauro, cujos elementos visuais merecem a atenção de Maria Coutinho, sem esquecer os conjuntos de textos ou imagens que são aqui convocados em torno de dois temas agregadores: os apocalipses, que Alicia Miguelez Cavero observa no contexto português a partir do comentário de Apríngio de Beja, das cópias dos beatos e do Apocalypsis Nova, e as trindades "trivúlcicas" nos livros da Biblioteca Nacional de Portugal examinadas por António-José de Almeida. A encabeçar o livro, os dois estudos introdutórios, da autoria de Adelaide Miranda e Maria João Melo o primeiro e de Inês Correia o segundo, não se fixam em nenhuma obra em particular, tendo por objetivo uma missão pedagógica mas também organizadora de toda a obra: fazer o enquadramento científico do manuscrito medieval na sua múltipla dimensão textual, visual e material, multiplicidade que se manifesta de modo excelente no códice.

De todas estas contribuições não poderia dar melhor conta do que já o fez Catarina Barreira no seu prefácio à obra, e limito-me, por isso, a expor modestamente a riqueza 
deste conjunto de textos, que faz jus ao seu título - Luz, cor e ouro - também eles lançando uma claridade muito particular sobre os manuscritos iluminados que constituem os seus objetos de estudo. Gostaria, no entanto, de sublinhar o modo particular, e diria mesmo, peculiar, como este livro convoca o leitor para um melhor conhecimento dos manuscritos medievais. Por um lado, pela interdisciplinaridade que é cada vez mais uma metodologia de trabalho inevitável para os estudiosos da Idade Média. Por outro lado, pela multidisciplinaridade inerente à própria composição e vida dos manuscritos em causa, que espelha, não só o modo multifacetado e compósito como a ciência se organizava nos centros de cultura e de saber da Idade Média, como também as modalidades de interpelação do público apelando a dispositivos que ultrapassavam a captação abstrata do conhecimento, demasiado restrita a recetores letrados, para se alargarem a outras formas de construção do sentido, mais centradas na materialidade dos manuscritos, que além de permitirem expandir o universo de receção também funcionavam como instrumento simbólico de consolidação do conhecimento, além de confirmarem o poder do seu dedicatário ou do proprietário. Também aqui fica magnificamente patente a necessidade imperiosa de se regressar aos manuscritos em todas as disciplinas dos estudos medievais, e de considerar menos a obra e mais o texto, ou seja, as manifestações textuais singulares que fazem do manuscrito uma obra em si, impossível de se subsumir ou de se fundir num conjunto de textos com os quais mantém relações, por vezes, muito distantes, sempre que existem vários exemplares de uma obra. Assim, a noção de leitura que está subjacente a esta obra decorre dos próprios objetos estudados, e é aqui devolvida de forma inexorável ao leitor moderno, assentando, precisamente, creio eu, em princípios que estão na base das análises expendidas por José A. Ramos, Luís Urbano Afonso e Tiago Moita nas admiráveis páginas que dedicam à questão da leitura da Bíblia no contexto específico, justamente, no artigo que assinam em conjunto sobre o códice sefardita de Cervera, e que eu tomo a liberdade de evocar como representativas de uma atitude comprometida perante a leitura, salvaguardando a situação específica das orientações massoréticas da leitura em que essas observações são proferidas: a codificação, ou seja a indicação por meio de dispositivos específicos, tópicos mas também materiais, da interpretação a seguir, a orientação do leitor no percurso de leitura do manuscrito como forma de construir o sentido de maneira inclusiva, onde o todo esteja simbólica e maravilhosamente refletivo.

Medievalista online № 22 | Julho - Dezembro 2017 ๑ IEM - Instituto de Estudos Medievais 6 www2.fcsh.unl.pt/iem/medievalista 
Assim, estes estudos de uma forma geral revelam que a vida dos manuscritos na Idade Média assenta num paradoxal balanço entre obscuridade e claridade. Ao relevarem os pormenores técnicos, históricos e artísticos da sua manufactura e circulação, colocam o leitor perante a evidência de que a obscuridade, que é inerente às dificuldades de uma escrita em larga medida cifrada, constitui um aspeto de valorização dos manuscritos cujo sentido se encontra elevado na medida da restrição do seu acesso. Todo o trabalho de iluminação ou de ilustração entra nesse jogo da significação capaz de proporcionar uma gratificação intelectual, mas também moral, ao leitor-decifrador em busca da chave do sentido, e nessa medida, como afirma Mary Carruthers no seu livro sobre a beleza na Idade Média, a iluminação faz parte da experiência estética como elemento inseparável do processo do conhecimento ${ }^{3}$. O valor da obra reside em grande parte no facto de oferecer ao leitor a oportunidade de se envolver numa conquista difícil, de procurar o sentido à custa de esforço, ou seja, de envolver a sua pessoa, tanto a mente como o corpo, no caminho até à interpretação, como, de resto, Santo Agostinho tinha proclamado já no De Doctrina Christiana. Porém, e é esta uma lição que também colhemos neste magnífico livro, o manuscrito iluminado torna igualmente patente que a obscuridade deve obedecer a uma rigorosa arquitetura dos elementos usados na codificação do sentido sob pena de o esclarecimento almejado, a claridade que se espera encontrar no final do percurso de leitura, se desvanecer no vago e no impreciso. Deste modo, o manuscrito iluminado alia o conhecimento oferecido em extensão a momentos de sintetização, que são privilegiados na exata medida da organização criteriosa dos seus elementos, e assim eles se oferecem na irredutível visibilidade da imagem estruturada.

Nestas páginas encontra o leitor incauto a magnífica oportunidade de se familiarizar, com o auxílio das mais sofisticadas ferramentas de análise, com momentos privilegiados da manifestação de uma cultura da imagem e da materialidade da escrita, aqui percorrendo as várias artes do conhecimento, desde as letras às ciências, como aqui poderá o leitor especializado ter o ensejo de aprofundar os seus conhecimentos graças aos frutos aqui apresentados de uma investigação muito atualizada que percorre um invulgar conjunto de manuscritos iluminados conservados em arquivos e bibliotecas

\footnotetext{
${ }^{3}$ CARRUTHERS, Mary - The Experience of Beauty in the Middle Ages. Oxford: Oxford University
} Press/Oxford-Warburg Studies, 2013, pp. 61-70.

Medievalista online № 22 | Julho - Dezembro 2017 @ IEM - Instituto de Estudos Medievais 7 www2.fcsh.unl.pt/iem/medievalista 
nacionais. Não só pelo valor dos estudos por si mesmos, mas também pela forma admirável como se soube valorizar um património medieval dos manuscritos iluminados, promovendo o conhecimento dinâmico dos documentos em leituras críticas, a Biblioteca Nacional de Portugal e o Instituto de Estudos Medievais estão de parabéns, bem como a coordenadora do volume, Doutora Catarina Barreira, que é responsável pela realização deste magnífico projeto de apresentação em livro dos estudos inicialmente proferidos em conferências no seminário um mês, um códice, e naturalmente, todos os autores que contribuíram para ele com o seu profundo saber.

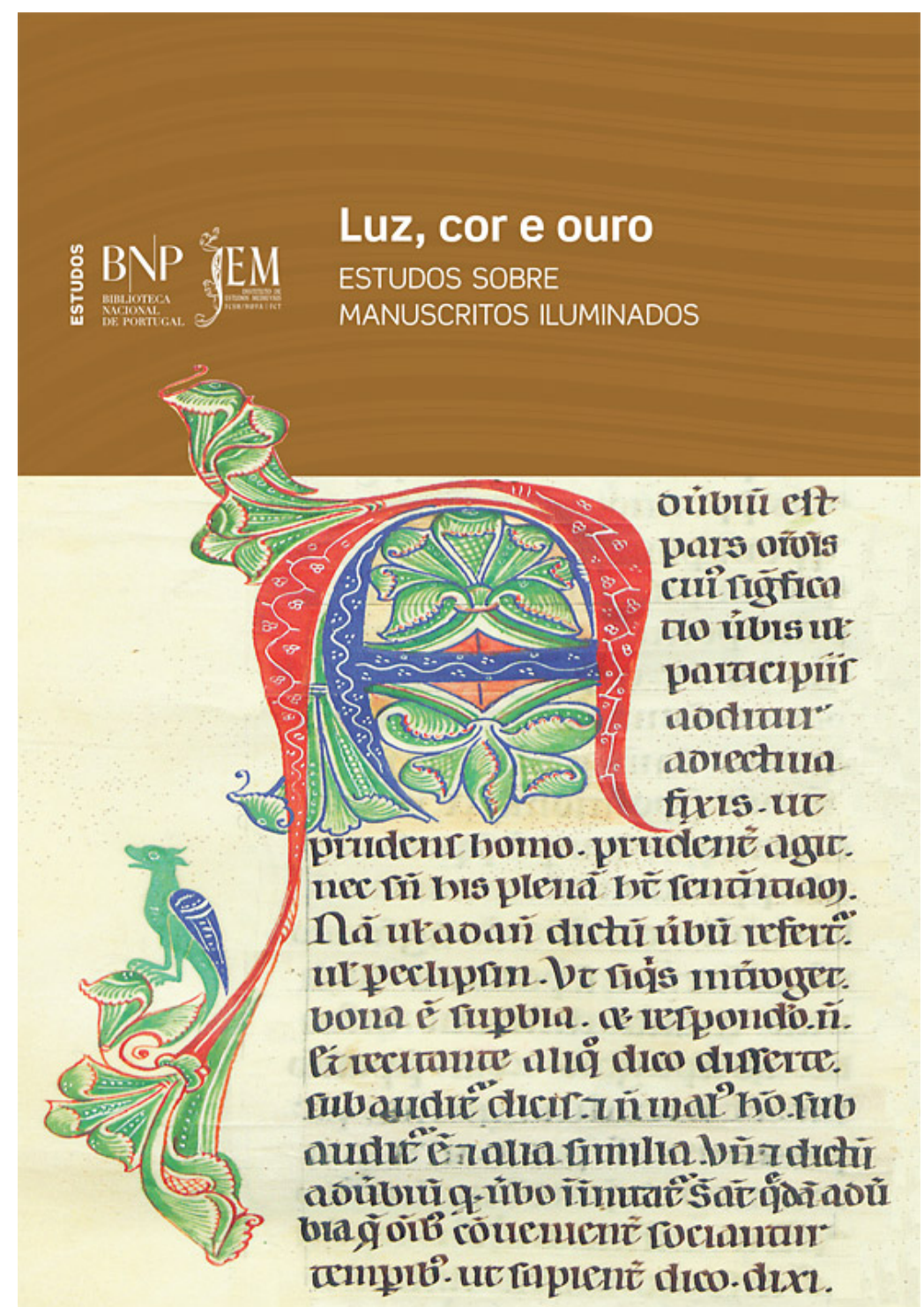

Figura 1 - Capa do livro. BARREIRA, Catarina Fernandes (coord.) - Luz, Cor e Ouro. Estudos sobre manuscritos iluminados. Lisboa: Biblioteca Nacional de Portugal/Instituto de Estudos Medievais, ISBN: 978-972-565-600-6 (ed. eletrónica). 


\section{COMO CITAR ESTE ARTIGO}

\section{Referência electrónica:}

MORAIS, Ana Paiva - "Luz, cor e ouro: estudos sobre manuscritos medievais.

Lançamento de e-book e apresentação da base de dados ManuscriPT”. Medievalista 22 (Julho-Dezembro 2017). [Em linha] [Consultado dd.mm.aaaa]. Disponível em http://www2.fcsh.unl.pt/iem/medievalista/MEDIEVALISTA22/morais2214.html ISSN 1646-740X.

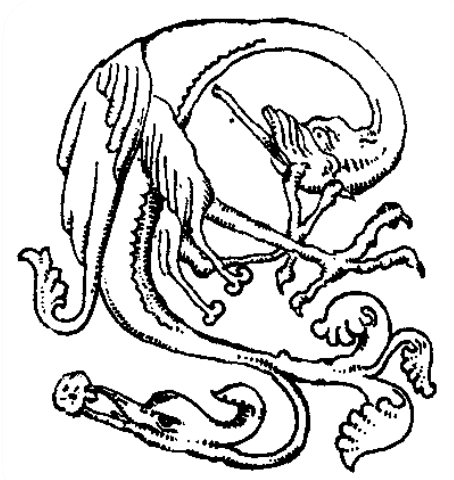

